\title{
Research of the Method to Develop Patriotism Education in Colleges and Universities under the New Media Environment
}

\author{
Yuzhen Du \\ Xi'an University of Science and Technology \\ Xi'an, Shaanxi 710054
}

\author{
Xiangyi Ji \\ Xi'an University of Science and Technology \\ Xi'an, Shaanxi 710054 \\ 275283021@qq.com
}

\begin{abstract}
Education in patriotism is an important part of ideological and political education in colleges and universities. The new media better meets the needs of college students with its rich content and fast dissemination methods. Meanwhile, the characteristics of the new media also cause the complexity of the educational environment. And the infiltration of Western ideology poses challenge to the education. Facing these challenges, we should innovate education ideas, enrich education content, innovate education vehicles, broaden the channel of education, and strengthen the supervision of the Internet so that new media can become an important way for patriotic education in colleges and universities.
\end{abstract}

Keywords-new media; colleges and universities; education in patriotism; method research

\section{THE NEW CHARACTERISTICS OF THE NEW MEDIA}

\section{A. Richer content}

Comparing with the traditional media, the new media has more active audience and richer content. Unlike the traditional media where ordinary people's voice in will be limited by factors such as personal social status, economic level, and knowledge, new media is different in that as long as one registers an account, he can express his feelings on Weibo, WeChat and other social media platforms, which does not require a strong knowledge base, proficient writing skills or social status. The speech control is more lenient and the review is less restrictive. Therefore, the content on the new media platform is richer than traditional media including politics, famous speeches, travel strategies, local customs, and entertainment gossip. In addition to traditional texts and pictures, there are webcasts, short videos, moving pictures, and online literature. Comparing with other social groups, students have more time and energy to be devoted on new media platforms and are more likely to accept new things. They are the recipients of information, and also publishers and disseminators. College students can write articles, edit videos and hold live broadcasts to enrich the content on the new media platform.

\section{B. Faster transmission}

In the era of traditional media, if somebody wants to publish a news article, he must first define its category, choose the format and platform, then start with the manuscripts, and it can't be printed and distributed until it undergoes examinations and reviews. After the examination, it will be printed and distributed. However, the speed of communication is slow, and interaction is poor, and information feedback is late. However, with new media, people all over the world can receive the latest information at any time through online and mobile platforms. Mobile netizens have become the main body of Internet users. By the end of December 2017, the number of Internet users in China had reached 772 million with the number of mobile netizens accounting for $97.5 \%$ of the total number of Internet users. The utilization rate of mobile instant messaging reached 93.3\%, and the number of mobile network news users reached 620 million. The WeChat's users who open up moment accounted for $87.3 \%$, and the number of users in webcasts was 422 million. The convenient network makes the information spread faster and the procedures before information release are greatly reduced. With the new media platform, publishers and recipients of information can communicate in a timely manner. The source of information can be any ordinary person who can publish information and receive information anywhere, anytime.

\section{Harder regulation}

As the government's sounders and propaganda tools, the traditional mainstream media are generally managed by the government. The manuscripts of these traditional media must be reviewed. For some of the news that is not urgent in time, such a review has little effect, but when emerging some unexpected events, the mainstream media may lose its initiative and cause rumors after the information censorship. New media are more likely to get the power of discourse at this time. With no direct contact with some media organizations, most of the new media users are not affected by some traditional organizations and do not need to go through the relevant agencies to publish information. Publishers can also hide their identities through a series of technical means. Therefore, the traditional media supervision methods are not fit for new media. It is more difficult to supervise the information on new media platforms in that both the source and the carrier of information release have undergone qualitative changes. 


\section{NEW CHALLENGES FOR THE DEVELOPMENT OF PATRIOTISM EDUCATION IN COLLEGES AND UNIVERSITIES UNDER THE NEW MEDIA ENVIRONMENT}

\section{A. Education condition vicissitude}

Anyone who registers on the new media platform can speak on it with few restrictions. As it is impossible to identify the authenticity of the information one by one, we can only block ban information by keywords due to the difficult website supervision, resulting in the wide spread of misleading information and malicious rumors. In addition, people believing in historical nihilism, with the aid of new media platforms, have fabricated, changed the history of the country and even the party, and smeared national heroes and revolutionary martyrs in the name of "real history" and "interpreting history". They took advantage of the of the network's information fragmentation to fabricate, rewrite the historical events, in order to achieve ulterior motives. The new media provides a platform for emotional venting for various morbid personalities, and also presents a channel for cybercrime organizations. In order to increase click-through rates and news views, many websites and new media platforms maliciously misrepresent the facts, or garble quote out of context to attract people. In this context, as the main targets of dissemination by new media, college students who are inexperienced and without complete outlooks are easily influenced by bad information, which makes the patriotic education environment in colleges and universities more complicated. [1]

\section{B. Imperfect supervisory system}

In the development of new media, supervision has always been a difficult problem. The popularity of the network brings people's further understanding of network knowledge. The methods of hiding IP have been very mature and difficult to trace, and the countless software has made it easy to cross the firewall. These emerging technological means make it increasingly difficult to regulate the whole network. The cost of fabricating online rumors and cybercrime are small. Therefore, these behaviors are difficult to effectively curb. In the online world, undergraduates do not have complete values, which, together with the influence of neo-liberalism, historical nihilism and other thoughts, will affect the launching of patriotism in colleges and universities.

\section{The infiltration of Western ideology}

The infiltration of Western ideology can be mainly categorized into two types: one is the traditional media; the other is the new media. The former generally directly promotes Western ideology through broadcasting, television, newspapers, books and magazines. However, the infiltration of new media has stronger disguise. Covered with universal values or mass culture, the content of Western ideology is dispersed in various fields. "The digital world is a new territory that can unleash indescribable production energy, but it can also be used as a tool for terrorists and tricks, and even as a base for big liar and malicious slander."'[2] The characteristics of the new media determined that it is an important position for western ideology to infiltrate our young students' life. The means of infiltration have become more diverse. People who look down upon
China's socialist road have used new media to indirectly promote bourgeois ideology, advocated Western "democracy" and "liberty" and diluted socialist ideology by domestic conflicts. "Internet is the individual-centered communication technology. Its flat structure and the network consensus generated by the media highlight and amplify the autonomy, diversity, selectivity and variability of people's ideological activities. Moreover, its natural anti-center, countermainstream, and non-ideological characteristics have led to a trend of digress, fragmentation, populist, keeping the Internet society in a counter-subconscious state and anarchist symptoms. It occasionally shows real and powerful public opinion force and social influence. Its negative effects caused by carelessness, improper control and unfavorable guidance, and the destructive power cannot be ignored."[3] To resist the infiltration of Western ideology, we must strengthen education in patriotism. We must ensure that the leadership of the party is not shaken, and actively guide college students and the public to believe that socialism with Chinese characteristics is a truth. We should stand firmly, and adhere to mainstream ideology, and then draw on the advantages of other cultures to improve ourselves.

III. THE METHODS TO ENHANCE PATRIOTISM EDUCATION IN COLLEGES AND UNIVERSITIES UNDER THE BACKDROP OF NEW MEDIA

\section{A. Innovating education idea and enriching teaching content}

New media platforms such as WeChat, Weibo, Douban, and Douyin have become necessary software for college students to socialize. To carry out patriotic education, colleges and universities should neither stick to the rules, nor focus only on the class. Instead, they need to actively study the new media platform, take the initiative to innovate the educational concept, and follow students' ideological dynamics. Moreover, they should make full use of the characteristics of the new media and infiltrate patriotic education into the daily life of college students. [4]

In terms of educational content, first of all, we must strengthen the traditional education of patriotism. We are a nation with 5,000 years of splendid culture. In ancient times, people had the consciousness of defending their clan tribes, which can be reflected from the legends of Shennong, Huangdi and Dayu. During the feudal period, there emerged many patriotic scholars and poets such as Wang Changling who declared "No Hu horses could ever cross the Yinshan" and Lin Zexu who sang "Were it to benefit my country I would lay down my life; what then is risk to me?” All These poets entertain their love for the country and their hope for the nation to write down these ancient verses. Their spirit also affects contemporary youth. In modern times, facing with Western powers that are stronger than us in economy, politics, and military, our forefathers did not flinch. There were six reformers (Tan Sitong, Kang Guangren, Lin Xu, Yang Shenxiu, Yang Rui and Liu Guangdi) who wanted to replace the feudalism with capitalism to rejuvenate our country, but were fiercely killed by conservatives led by Empress Dowager Cixi. Dr. Sun Yat-sen strove for revolution at the expense of all his fortune, ends even at the end of his life, never forgot the future of the country and the nation. During the period of the War of 
Resistance against Japanese Aggression, there were five heroes on Langya Mountain facing death unflinchingly, and Zhang Zizhong killing thousands of enemies died for the country in the battlefield. All these great people sacrificed their precious lives for the Chinese people to rise to their feet. In the new media environment, patriotic education in colleges and universities is to encourage college students to learn the spirit of perseverance.

Second, we must launch education in the national security which is the basic condition for the survival and development of a country. In the face of an increasingly complex security environment, the anti-China forces and terrorism at home and abroad, it is necessary and very important to form the views of national security. With the development of economy and technology and the popularity of the Internet, the factors that affect national security become intricate. Colleges and universities are the cradle of national talents. The ideology of students is related to the future development of the country. Therefore, we should focus on the education of the view of national security concept, so that college students have a high sense of responsibility which is also a part of the comprehensive quality of college students. Education of the view of national security can enable university students to have a clearer and deeper understanding of the economic, political, military, and diplomatic aspects of the world today.

Next, we must carry out education of national conditions for it is a must for college students. Only if students have a deep understanding of the basic national conditions can they establish a lofty ideal and belief and formulate a reasonable life plan based on facts. Mao Zedong once said "understanding China's national conditions is the basis for recognizing all revolutionary issues.” In the long history of development, it is because our Party has been able to have a clear and profound understanding of China's basic national conditions that it can lead its people to accomplish historical missions at the time of the crisis. Through the education of national conditions, college students can understand the basic national conditions, and on this basis, work hard for the future of the motherland.

Finally, we should pass on to students' rational patriotism. "The simple and strong patriotic enthusiasm of university students is of course very precious, but rational patriotic expressions and social behaviors are more important in a complex international and domestic environment. First, educating college students recognize that patriotism is not an emotional catharsis, but the deep feelings for the country's recognition and support and the acts of safeguarding the interests and dignity of the nation and the country. Second, we can improve the comprehensive quality of college students by nurturing a good attitude of openness, tolerance and selfconfidence, and the ability to calmly analyze problems and discriminate right and wrong. Third, we should cultivate college students to express their patriotic feelings with a responsible and peaceful attitude in a moral framework, to civilized, and orderly, rationally, and legally practice patriotic behavior in line with the rule of law. Forth, instruct students to integrate patriotism to their own study and life, embodying the patriotic spirit in various acts of daily life."[5]

\section{B. Innovating education carrier and broadening the channel for education}

First, we can make patriotic education more diversified, not limited to traditional classroom and book education through the use of new media platforms such as WeChat, Weibo, and Zhihu. Once the platform is set up, it is necessary to update the content in a timely manner, keep up with the trend of the times, and pay attention to hot topics in university, forming a good interaction with students. Educate college students in patriotism in a relaxed and pleasant atmosphere.

Second, Make patriotic education come into the daily life of students by the use of film and television, novels and other means which are more easily accepted by students. For example, The Founding of a Republic, Beginning of the Great Revival and Assembly produced by China Film Group Corporation, has become popular among students because of their all-star cast. The latest Operation Red Sea, Wolf Warriors and other films have demonstrated the strength of our country and inspired students' patriotism and generate their feelings that peace does come easily. It is also possible to publicize the ancestral heroes' deeds and heroic sprits to influence the students.

Furthermore, we can adopt mobile games, online games, and live broadcast to promote patriotic figures. According to the 41st China Internet Statistics Development Report, the use rate of mobile internet games has reached 54.1\%. The number of webcast users reached 422 million. We must appropriately use such platforms as "Arena of Valor" to enable students to learn about historical knowledge and the life story of characters while playing games, so as to enhance their identification of national culture, and resist the historical nihilism.

Finally, the fan culture can be applied appropriately to create a group environment that is conducive to student social identity. The power of role models is enormous. In the current society, the number of the fans of a star or "big V" easily reaches tens of millions, and colleges and universities can use fans to develop education. "If individuals view themselves as members of a group, they tend to compare this group with other groups and look for differences. It is important to emphasize the differences between groups, and to distinguish the in-group from the out-groups based on its good performance. As a result, the in-group has acquired positive specificity, and a more positive social identity than the outgroups, giving the individual a positive self-evaluation, selfvalue and self-esteem.”[6] There is a popular young boy group named "TFboys" whose fans claim them as "four-leaf clover". Under the call of their idols, they have appealed for donations for poor areas and visited veterans of the war for many times. The creators of "Soldiers Sortie" - a television drama displayed in 2008, set up a fan group called "Happiness Time" which, since 2008, has been contributing to the povertystricken mountain areas and donating to build an elementary school called "Happiness Time" and has donated to the Yunnan Youth Development Foundation for many times. What's more, many fans chose to join the army to protect their homes. It has been 10 years since the drama be aired. This group is still active on the major new media platforms. When carrying out patriotic education, colleges and universities 
should pay attention to the "fans" group and create an environment conducive to students' self-identity in daily management, thereby generating a strong patriotic feeling. Through the publicity of celebrities and role models to influence the thinking and behavior of college students, we can foster students to understand that patriotism is not achieved by words but by deeds. As the saying goes, "when we see a man of virtue and talent, we should think of equaling them", it is the same case with role models and students.[7]

\section{Strengthening supervision over the Internet}

First of all, the development of the new media on campus has become overwhelming. Apart from the necessary official website building, there should be some accounts to deliver message on the platform where students gather, for example, the WeChat, Weibo, Zhihu, Douban and other forums which are essential for students' daily learning and life. Encountering emergency, we can firmly grasp the opportunity to speak, preventing the survival of false information.

Secondly, we should improve related network management regulations and purify the network environment to create a harmonious and friendly campus network atmosphere. We need to delete bad information and refute rumors in a timely manner. It is also necessary to set up a dedicated management and operation team. The members must have certain knowledge and technology professionals to be responsible for the normal maintenance of the website and the major new media platforms as well as information security. In addition, members should also include students in the school to be accessed to the latest news and curb the spread of bad information.

\section{CONCLUSION}

New media is just a new medium. It is unavoidable to emerge two-sided nature in its development, which causes the complexity of the patriotic education environment in colleges and universities. Therefore, facing the challenges, we must first strengthen patriotism education, and form various patriotic education methods that are rich in content by innovation. Second, we must build, manage, and use well the platform of new media. New media is the product of the development of the times. Giving full play to its role in the education of patriotism is our responsibility and also a requirement of patriotic education.

\section{REFERENCES}

[1] Zhang X, University B M. Innovative Research on Students' Patriotis m Education under the New Media Environment[J]. Journal of Shandong Youth University of Political Science, 2014.

[2] Institute of Marxis m of Chinese Academy of Social Sciences: Makesi Engesi Liening Lun Yishi Xingtai,Beijing: People's Publishing House,2009.(In Chinese)

[3] Liu Yongzhi. New Trends of Western Ideology Network Penetration and Countermeasures in China[J]. Studies on Marxism,2017(12):96-105. (In Chinese)

[4] Liu Y. On Patriotic Education Innovation of College Ideological and Political Theory Course under the Condition of New Media[J]. Education \& Teaching Research, 2016.

[5] Li Qiong.The Effective Path to College Students' Patriotism Education in the New Situation[J]. Journal of Ideological \& Theoretical Education ,2017(04):143-147. (In Chinese)

[6] Yan Ding:Social Identity Theory and Research Status, Psychology: Techniques and Application,2016(4):550. (In Chinese)

[7] Liu Hailong. Be a Patriot Like a Fan: New Media and the Birth of Fan Nationalism[J]. Modern Communication (Journal of Communication University of China), 2017,39(04):27-36. (In Chinese) 